\title{
S.I.Komar, M.D.Alyakrinskaya
}

\section{The importance of lipid peroxidation measurement in exhaled breath condensate for diagnosis of ventilator-associated pneumonia}

\begin{abstract}
Summary
Exhaled breath condensate was studied in 83 intubated patients and 38 healthy volunteers. Lipid peroxidation (diene conjugates, ketodienes, coupled trienes, Schiff's base, fatty acids with polyunsaturated links (substrate for oxidation), and antioxidant catalase) was measured by the spectrophotometric method. Nosocomial (ventilator-associated) pneumonia occurred in 38 patients intubated after surgical intervention or trauma. In those patients without pneumonia, levels of catalase and secondary / final lipid peroxidation products did not differ from that of healthy individuals but levels of conjugated dienes and polyunsaturated fatty acids were moderately increased (1.7-fold and 1.9-fold, respectively). Ventilator-associated pneumonia in intubated patients was accompanied by a significant increase in primary, secondary, and final lipid peroxidation products in exhaled breath condensate (11-fold; 9-fold and 8-fold, respectively, compared to the patients without pneumonia). The intensity of the oxidative stress in the lungs was related to the extension of pneumonia, severity of the respiratory insufficiency and poor outcome rate. To diagnose ventilator-associated pneumonia, cut-points for lipid peroxidation parameters were identified.

Key words: hospital-acquired pneumonia, exhaled breath condensate, lipid peroxidation.
\end{abstract}

\section{Резюме}

Было проведено исследование конденсата выдыхаемого воздуха (КВВ) 83 интубируемых хирургических больных и 38 здоровых добровольцев. Методом спектрофотометрии определялись показатели перекисного окисления липидов: диеновые конъюгаты, кетодиены и сопряженные триены, основания Шиффа, а также жирные кислоты с полиненасыщенными связями (субстрат для окисления) и антиоксидант каталаза. Нозокомиальная пневмония (НП) развилась у 38 интубируемых пациентов на фоне тяжелого хирургического заболевания или травмы. У интубируемых пациентов без развития НП содержание каталазы, вторичных и конечных продуктов липопероксидации не отличалось от здоровых лиц, но умеренно увеличивалось количество диеновых конъюгатов и полиненасыщенных жирных кислот (в 1,7 и 1,9 раза соответственно). Присоединение вентилятор-ассоциированной пневмонии (ВАП) у интубируемых пациентов сопровождалось значительным увеличением первичных, вторичных и конечных продуктов перекисного окисления липидов в КВВ (в 11, 9 и 8 раз соответственно) в сравнении с больными без пневмонии. Выраженность оксидативного стресса в легких коррелировала с размерами пневмонии, тяжестью дыхательной недостаточности, частотой неблагоприятных исходов. Разработаны диагностически значимые уровни показателей липопероксидации для распознавания ВАП.

Ключевые слова: нозокомиальная пневмония, исследование конденсата выдыхаемого воздуха, показатели перекисного окисления липидов.

Нозокомиальная пневмония (НП) встречается в практике врачей любых специальностей, но наиболее часто - в отделениях интенсивной терапии и хирургии [1]. По распространенности она занимает 2-е место после внегоспитальной пневмонии, а по летальности находится на 1-й позиции [2]. У больных, получающих продленную искусственную вентиляцию легких (ИВЛ), развивается особый вариант НП - т. н. "вентилятор-ассоциированная пневмония" (ВАП), она увеличивает продолжительность лечения в ОРИТ и у > 1/3 больных приводит к смертельному исходу [3]. Диагностика ВАП сопряжена с трудностями, клинические и рентгенологические критерии пневмонии у больных, находящихся на ИВЛ, нередко оказываются не вполне надежными [4]. Поэтому актуальной представляется разработка новых методов диагностики ВАП.
Перспективным субстратом для поиска маркеров пневмонии является конденсат выдыхаемого воздуха (KBВ). Это биологическая жидкость, испарившаяся с поверхности альвеол и воздухоносных путей. Поскольку площадь альвеолярной поверхности многократно превышает размеры поверхности верхних дыхательных путей, исследователи рассматривают анализ состава КВВ как уникальную возможность для неинвазивного изучения биохимизма легких [5-8]. И действительно, в КВВ обнаружено > 200 различных химических соединений, некоторые из них являются биомаркерами патологических процессов [9]. Представленная работа является 2-м этапом исследования, на 1-м этапе которого изучали состав КВВ у больных внегоспитальной пневмонией [8].

Цель настоящей работы - проанализировать диагностическую ценность исследования показателей 
перекисного окисления липидов (ПОЛ) в конденсате выдыхаемого воздуха у больных вентилятор-ассоциированной пневмонией. В доступной литературе мы не встретили данных о состоянии показателей оксидативного стресса у больных ВАП.

\section{Материалы и методы}

При заборе конденсата выдыхаемого воздуха за основу взята методика Г.И.Сидоренко и др. [5]. Устройство для забора конденсата представляло собой спиралевидную стеклянную трубку, соединенную с резиновым загубником, которая была запаяна в стеклянный цилиндр, куда поступала охлажденная до $0{ }^{\circ} \mathrm{C}$ вода. Исследуемые выдыхали воздух через упомянутую систему, он, проходя через спиралевидную трубку, охлаждался, и образовавшийся конденсат постепенно вытекал в сосуд для его сбора. В течение 20 мин получали 3 мл конденсата, который имел вид чистой, прозрачной жидкости, без макроскопически определяемой примеси слюны, реакция на белок слюны в конденсате всегда была отрицательной. У интубированных больных, находящихся на ИВЛ, конденсат получали из приспособления т. н. "уловителя конденсата", предусмотренного конструкцией аппаратов для ИВЛ. Замкнутая система "аппарат ИВЛ - дыхательные пути больного" исключала контаминацию слюной или посторонними частицами из окружающей среды. В КВВ методом спектрофотометрии определялись следующие показатели перекисного окисления липидов: общие полиеновые (жирные кислоты с полиненасыщенными связями - субстрат для ПОЛ), диеновые конъюгаты (первичные продукты ПОЛ), кетодиены и сопряженные триены (вторичные продукты ПОЛ) и основания Шиффа (конечные продукты ПОЛ). Эти соединения определяли в изопропанольной фазе липидного экстракта [10] по поглощению монохроматического светового потока липидным экстрактом в ультрафиолетовой части спектра: при длине волны 220 нм - общие полиеновые, 233 нм диеновые конъюгаты, 278 нм - диенкетоны с сопряженными триенами, 400 нм - основания Шиффа. Экстрагирующим веществом являлся изопропиловый спирт высокой степени чистоты. Концентрацию продуктов ПОЛ выражали в условных единицах экстинции (Е) на 1 мл КВВ с учетом разведения, т. е. Е 220 / мл, Е 233 / мл, Е 278 / мл, Е 400 / мл. Для оценки антиоксидантной защиты в конденсате определяли каталазу [10].

Результаты выражали по системе СИ в мкат / л, что означает количество перекиси водорода, расщепившейся каталазой, содержащейся в 1 л конденсата в секунду.

Были обследованы 111 человек, в т. ч. 83 больных, находящихся на ИВЛ (38 больных с ВАП и 45 пациентов группы сравнения без ВАП) и 38 практически здоровых добровольцев. Сравниваемые группы больных, находящихся на ИВЛ (с ВАП и без нее), стандартизированы по полу, возрасту, характеру основного заболевания и тяжести состояния, а также по длительности пребывания на ИВЛ. Группы были репрезентативны.

ВАП диагностировали на основании следующих критериев [4]:

1) появление нового инфильтрата на рентгенограмме, возникшего через $\geq 48$ ч после начала ИВЛ в сочетании с двумя из 3 следующих признаков:

- $\mathrm{t}^{\circ}>38,3{ }^{\circ} \mathrm{C}$;

- лейкоцитоз $\geq 10 \times 10^{9} /$ л;

- гнойный характер аспирата из трахеи;

2) отсутствие признаков легочной инфекции при поступлении в стационар.

В группе больных с ВАП преобладали мужчины, $>1 / 2$ этих пациентов были старше 60 лет (76 в долях единицы), средний возраст - 55,20 $\pm 2,58$ года. НП возникала на фоне тяжелого хирургического заболевания или травмы [1]. У всех больных с ВАП имелись критерии тяжелого течения. У 19 из 38 пациентов тяжесть состояния определялась самой ВАП. Многодолевое поражение легких было диагностировано у 13 человек (0,31 в долях единицы), деструкция легких - у 3 больных $(0,08)$, быстрое прогрессирование размеров пневмонии - у 3 , осложнение респираторным дистресс-синдромом - у $2(0,05)$, артериальная гипоксемия - у $7(0,18)$. В данной выборке среди возбудителей ВАП наиболее часто обнаруживались следующие возбудители: синегнойная палочка $(0,28)$, грамотрицательные бактерии кишечной группы $(0,24)$, комбинированная микрофлора $(0,24)$. Исход ВАП заболевания был благоприятным у 12 из 38 больных, у остальных 26 человек наступил летальный исход, у всех умерших получено морфологическое подтверждение НП.

\section{Результаты и обсуждение}

В табл. 1 представлены данные о содержании продуктов ПОЛ у больных с ВАП в сравнении со здоровыми лицами и группой патологического контроля. У пациентов, находящихся на ИВЛ без развития пневмонии, в КВВ выявлено небольшое увеличение общих полиеновых и первичных продуктов ПОЛ (в 1,9 и 1,7 раза соответственно), тогда как уровень вторичных и конечных продуктов ПОЛ и активность антиоксиданта каталазы не отличались от здоровых лиц. Умеренное увеличение полиненасыщенных жирных кислот в конденсате можно объяснить гипервентиляцией во время ИВЛ и повышенной потерей сурфактанта, а небольшой рост содержания первичных продуктов ПОЛ может указывать на начальную, обратимую стадию активации ПОЛ, что, возможно, является проявлением основного заболевания.

Совершенно другие данные получены у больных с госпитальной пневмонией, развившейся на фоне ИВЛ. Зарегистрирован многократный рост всех изучаемых показателей. Содержание полиненасыщенных жирных кислот (общих полиеновых) в среднем в 11 раз выше, чем в группе пациентов без ВАП. Это признак значительного усиления мембранодеструктивных процессов и деградации легочного 

в сравнении с группой контроля

\begin{tabular}{|c|c|c|c|c|c|c|}
\hline \multirow[t]{2}{*}{ Показатели } & \multirow[t]{2}{*}{ Здоровые } & \multicolumn{2}{|c|}{ Больные на ИВЛ } & \multirow[t]{2}{*}{$p_{1-2}$} & \multirow[t]{2}{*}{$p_{1-3}$} & \multirow[t]{2}{*}{$p_{2-3}$} \\
\hline & & с ВАП & без ВАП & & & \\
\hline Общие полиеновые, Е 220 / мл & $0,093 \pm 0,017$ & $2,05 \pm 0,25$ & $0,179 \pm 0,019$ & $<0,001$ & $<0,05$ & $<0,01$ \\
\hline Диеновые конъюгаты, Е 233 / мл & $0,073 \pm 0,013$ & $1,4 \pm 0,23$ & $0,125 \pm 0,016$ & $<0,001$ & $>0,05$ & $<0,001$ \\
\hline Диенкетоны и сопряженные триены, Е 278 / мл & $0,079 \pm 0,009$ & $0,70 \pm 0,18$ & $0,075 \pm 0,008$ & $<0,001$ & $>0,05$ & $<0,001$ \\
\hline Основания Шиффа, Е 400 / мл & $0,018 \pm 0,003$ & $0,14 \pm 0,06$ & $0,017 \pm 0,004$ & $<0,05$ & $>0,05$ & $<0,001$ \\
\hline Каталаза, мкат / л & $5,960 \pm 0,809$ & $11,47 \pm 2,32$ & $5,42 \pm 0,51$ & $>0,05$ & $>0,05$ & $<0,05$ \\
\hline
\end{tabular}

сурфактанта, компоненты которого обнаруживаются в конденсате. О том, что именно резчайшая интенсификация ПОЛ является причиной этих изменений, свидетельствует многократное увеличение первичных, вторичных и конечных продуктов ПОЛ в КВВ - в 11, 9 и 8 раз соответственно. Уровень антиоксиданта каталазы увеличивался только вдвое, что может отражать дисбаланс в системе "ПОЛ-антиоксиданты" в сторону преобладания продуктов ПОЛ.

Важнейшим фактором риска ВАП является длительность ИВЛ. Если в 1-е сут. риск НП невелик, то после 72 ч он возрастает на $50 \%$, на 8-10-е сут. ВАП обнаруживается у $80 \%$ пациентов, через 2 нед. у всех больных [11].

С учетом вышеизложенного было изучено содержание маркеров оксидативного стресса в КВВ в разные периоды пребывания на ИВЛ у больных госпитальной пневмонией (табл. 2). Максимум активации ПОЛ зарегистрирован на 3-5-е сут. ИВЛ - именно тогда угроза ВАП становится наиболее реальной. В дальнейшем уровень интенсификации ПОЛ несколько снижается, что обусловлено реакцией на лечебные мероприятия по санации бронхов и антибактериальную терапию. Однако он остается повышенным в течение всего последующего периода заболевания.

Развитие нозокомиальной пневмонии у пациентов, получающих ИВЛ, является пусковым моментом формирования полиорганной недостаточности, которая и обусловливает высокую летальность среди этих больных. В табл. 3 представлены данные о содержании изучаемых продуктов ПОЛ в КВВ больных с различным исходом госпитальной пневмонии. У больных с ВАП, приведшей к смерти, содержание диенкетонов и сопряженных триенов было достоверно выше, чем в группе пациентов с благоприятным исходом. Осложненное течение НП сопровож- далось более высоким уровнем диенкетонов $(1,09$ и $0,52 \mathrm{E} /$ мл; $p<0,05)$.

О том, что именно НП является причиной резкой интенсификации процессов ПОЛ в легких, свидетельствуют и данные корреляционного анализа. Выявлена высокая корреляционная зависимость между распространением пневмонии и концентрацией полиненасыщенных жирных кислот, а также первичных продуктов ПОЛ в КВВ $(p=0,99 ; p<0,05)$. Обнаружена связь между выраженностью дыхательной недостаточности и показателями ПОЛ в КВВ. Снижение насыщения крови кислородом сопровождалось увеличением концентрации общих полиеновых $(p=-0,54)$ и диеновых конъюгатов ( $p=-0,31)$, а прогрессирование артериальной гиперкапнии - ростом уровня первичных продуктов ПОЛ $(p=0,32 ; p<0,05)$.

Рассчитаны диагностически значимые диапазоны показателей ПОЛ в КВВ, позволяющие распознать высокий риск развития НП у больных, находящихся на ИВЛ (табл. 4). Наиболее информативным, по данным исследования показателей ПОЛ в КВВ, является увеличение общих полиеновых, диеновых конъюгатов и диенкетонов.

Эти данные свидетельствуют о том, что динамическое исследование вышеназванных показателей ПОЛ в КВВ у больных, находящихся на продленной ИВЛ, может способствовать более раннему распознаванию госпитальной пневмонии.

\section{Заключение}

У больных без НП, получающих ИВЛ, содержание диенкетонов, оснований Шиффа и каталазы в КВВ не отличается от аналогичных показателей у здоровых лиц. Развитие госпитальной пневмонии у хирургических пациентов, находящихся на продленной ИВЛ, сопровождается изменениями состава КВВ,

Таблииа 2

Динамика показателей липопероксидации в КВВ у больных ВАП

\begin{tabular}{|c|c|c|c|c|}
\hline \multirow[t]{2}{*}{ Показатели } & \multicolumn{4}{|c|}{ Период ИВЛ } \\
\hline & 1-2-й день & 3-5-й день & 6-10-й день & $>10$ дней \\
\hline Общие полиеновые, Е 220 / мл & $0,33 \pm 0,05^{*}$ & $2,70 \pm 0,97^{*}$ & $1,27 \pm 0,26^{*}$ & $1,32 \pm 0,44^{*}$ \\
\hline Диеновые конъюгаты, Е 233 / мл & $0,25 \pm 0,03^{*}$ & $1,84 \pm 0,83$ & $0,89 \pm 0,31^{*}$ & $0,85 \pm 0,32 * *$ \\
\hline Кетодиены и сопряженные триены, Е 278 / мл & $0,130 \pm 0,016^{*}$ & $0,94 \pm 0,53$ & $0,37 \pm 0,07$ & $0,38 \pm 0,13^{*}$ \\
\hline Основания Шиффа, Е 400 / мл & $0,030 \pm 0,017$ & $0,34 \pm 0,29$ & $0,390 \pm 0,014$ & $0,0035 \pm 0,0090$ \\
\hline Каталаза, мкат / л & $8,95 \pm 3,16$ & $22,45 \pm 9,39$ & $11,05 \pm 4,05$ & $6,01 \pm 0,28$ \\
\hline
\end{tabular}

Примечание: * $-p<0,05$. 
Таблица 3

Показатели ПОЛ и каталаза в КВВ у больных ВАП с благоприятным и летальным исходом

\begin{tabular}{|c|c|c|c|}
\hline \multirow[t]{2}{*}{ Показатели } & \multicolumn{2}{|c|}{ Исход } & \multirow{2}{*}{$\begin{array}{l}\text { Критерий } \\
\text { инверсий }\end{array}$} \\
\hline & выздоровление & летальный & \\
\hline $\begin{array}{l}\text { Общие полиеновые, } \\
\text { Е } 220 \text { / мл }\end{array}$ & $1,64 \pm 0,33$ & $2,24 \pm 0,33$ & $>0,05$ \\
\hline $\begin{array}{l}\text { Диеновые конъюгаты, } \\
\text { Е } 233 \text { / мл }\end{array}$ & $1,00 \pm 0,18$ & $1,58 \pm 0,32$ & $>0,05$ \\
\hline $\begin{array}{l}\text { Диенкетоны } \\
\text { и сопряженные } \\
\text { триены, E } 278 \text { / мл }\end{array}$ & $0,40 \pm 0,08$ & $0,84 \pm 0,26$ & $<0,05$ \\
\hline $\begin{array}{l}\text { Основания Шиффа, } \\
\text { Е } 400 \text { / мл }\end{array}$ & $0,10 \pm 0,07$ & $0,160 \pm 0,009$ & $>0,05$ \\
\hline Каталаза, мкат / л & $8,11 \pm 1,58$ & $13,50 \pm 3,51$ & $>0,05$ \\
\hline
\end{tabular}

Таблица 4

Биомаркеры ВАП, по данным исследования КВВ

\begin{tabular}{|c|c|c|}
\hline Показатели поЛ & Чувствительность, \% & Специфичность, \% \\
\hline $\begin{array}{l}\text { Общие полиеновые >0,42; } \\
\text { Е } 220 \text { / мл }\end{array}$ & 100 & 100 \\
\hline $\begin{array}{l}\text { Диенконъюгаты 0,33; } \\
\text { Е } 233 \text { / мл }\end{array}$ & 97 & 98 \\
\hline $\begin{array}{l}\text { Диенкетоны и сопряженные } \\
\text { триены >0,2; Е 278 / мл }\end{array}$ & 86 & 96 \\
\hline
\end{tabular}

характерным для резко выраженной активации свободно-радикального окисления: многократно возрастает концентрация общих полиеновых, а также первичных, вторичных и конечных продуктов ПОЛ. Выраженность оксидативного стресса в легких, по данным исследования КВВ у больных ВАП, коррелирует с распространением пневмонии, с тяжестью дыхательной недостаточности, частотой осложнений и неблагоприятных исходов. Увеличение общих полиеновых, диеновых конъюгатов и кетонов в КВВ больных, находящихся на ИВЛ, может рассматриваться в качестве биомаркеров высокого риска госпитальной пневмонии. Разработаны диагностически значимые уровни этих показателей для распознавания ВАП.

\section{Литература}

1. Гельфанд Б.Р., Белоцерковский Б.З., Проценко Д.Н. Нозокомиальная пневмония в хирургии: Метод. рекомендации РАСХИ. М.; 2003. 5-6.
2. Комар С.И. Структура летальности при пневмонии у взрослых лиц. В кн.: Чучалин А.Г. (ред.). Актуальные проблемы пульмонологии. М.: Универсум Паблишинг; 2000. 313-319.

3. Hospital-acquired Pneumonia Guideline Committee of the American Thoracic Society \& Infection Diseases Society of America. Guidelines for the management of adults with hospital-acquired pneumonia, ventilator-associated pneumonia and healthcare-associated pneumonia. Am. J. Respir. Crit. Care Med. 2005; 171 (4): 388-416.

4. Чучалин А.Г., Синопальников А.И., Страчунский Л.С. и др. Нозокомиальная пневмония у взрослых: практические рекомендации по диагностике, лечению и профилактике. Пособие для врачей. Пульмонология 2005; 3: 13-36.

5. Сидоренко Г.И., Зборовский Э.И., Левина Д.И. Поверхностно-активные свойства конденсата выдыхаемого воздуха (новый способ исследования функции легких). Tep. арx. 1980; 3: 65-68.

6. Бестужева С.В. Физико-химическое и биохимическое исследование конденсата паров выдыхаемого воздуха: Метод. рекомендации. Минск; 1983.

7. Анаев Э.Х., Авдеев С.Н., Чучалин А.Г. Исследование РН конденсата выдыхаемого воздуха при воспалительных заболеваниях легких. Пульмонология 2005; 5: 75-79.

8. Алякринская М.Д. Значение определения показателей перекисного окисления липидов в конденсате выдыхаемого воздуха в диагностике и прогнозе внегоспитальной и нозокомиальной вентилятор-ассоциированной пневмонии: Автореф. дис. ... канд. мед. наук. Челябинск; 2007.

9. Анаев Э.Х., Чучалин А.Г. Исследование конденсата выдыхаемого воздуха в пульмонологии: обзор зарубежной литературы. Пульмонология 2005; 5: 75-79.

10. Показатели липидного обмена в сыворотке крови практически здорового населения, проживающего в ЮжноУральском регионе в условиях адаптации к климатическим и техногенным воздействиям: Метод. рекомендации / Коробейникова Э.Н., Зурочка А.В., Евдокимова Е.В. и др. Челябинск; 2002.

11. Гайдуль К.В., Лимонов В.Л., Муконин А.А. Нозокомиальная пневмония: этиология, патогенез, диагностика и лечение: Информ. пособие для практ. врачей. Новосибирск: Науч.-информ. центр ООО "АБОЛмед"; 2004.

\section{Информация об авторах}

Комар Светлана Ивановна - д. м. н., проф. кафедры пропедевтики внутренних болезней Челябинской государственной медицинской академии Росздрава; тел.: (351) 237-79-16

Алякринская Марина Дмитриевна - к. м. н., старший преподаватель кафедры патофизиологии Челябинской государственной медицинской академии Росздрава; тел.: 8-919-111-91-98; e-mail: amd07 @inbox.ru 